\title{
Health burden in (pre)diabetes and the role of cardiovascular function
}

Citation for published version (APA):

Veugen, M. (2019). Health burden in (pre)diabetes and the role of cardiovascular function: extensive phenotyping in a population-based approach. [Doctoral Thesis, Maastricht University]. Gildeprint Drukkerijen. https://doi.org/10.26481/dis.20191211mv

Document status and date:

Published: 01/01/2019

DOI:

10.26481/dis.20191211mv

Document Version:

Publisher's PDF, also known as Version of record

\section{Please check the document version of this publication:}

- A submitted manuscript is the version of the article upon submission and before peer-review. There can be important differences between the submitted version and the official published version of record.

People interested in the research are advised to contact the author for the final version of the publication, or visit the DOI to the publisher's website.

- The final author version and the galley proof are versions of the publication after peer review.

- The final published version features the final layout of the paper including the volume, issue and page numbers.

Link to publication

\footnotetext{
General rights rights.

- You may freely distribute the URL identifying the publication in the public portal. please follow below link for the End User Agreement:

www.umlib.nl/taverne-license

Take down policy

If you believe that this document breaches copyright please contact us at:

repository@maastrichtuniversity.nl

providing details and we will investigate your claim.
}

Copyright and moral rights for the publications made accessible in the public portal are retained by the authors and/or other copyright owners and it is a condition of accessing publications that users recognise and abide by the legal requirements associated with these

- Users may download and print one copy of any publication from the public portal for the purpose of private study or research.

- You may not further distribute the material or use it for any profit-making activity or commercial gain

If the publication is distributed under the terms of Article $25 \mathrm{fa}$ of the Dutch Copyright Act, indicated by the "Taverne" license above, 


\section{Nederlandstalige samenvatting}

Type 2 diabetes mellitus is een chronische stofwisselingsziekte gekenmerkt door verhoogde glucosewaardes in het bloed, ook wel hyperglykemie genoemd. Op de lange termijn kunnen deze verhoogde glucosewaardes leiden tot chronische schade aan nieren (nefropathie), zenuwen (neuropathie) en de ogen (retinopathie). Daarnaast verdubbelt type 2 diabetes het risico op het krijgen van cardiovasculaire ziekten zoals een hartinfarct, perifeer arterieel vaatlijden en een beroerte. Dit wordt deels verklaard door een ongunstig risicoprofiel met cardiometabole risicofactoren zoals een hoog cholesterol (dislipidemie), overgewicht (obesitas) en hoge bloeddruk (hypertensie). Nefropathie, neuropathie, retinopathie en cardiovasculaire ziekten worden ook wel de klassieke complicaties van type 2 diabetes genoemd. Recent onderzoek laat echter zien dat ook niet-klassieke comorbiditeiten zoals cognitieve achteruitgang en depressie mogelijk bijdragen aan het verhoogde risico op overlijden bij type 2 diabetes. Daarmee is de totale ziektelast in type 2 diabetes mogelijk nog groter dan we denken. Type 2 diabetes is een van de meest prevalente ziektes wereldwijd en is een van werelds grootste gezondheidsuitdagingen die blijft groeien. In 2017 waren er naar schatting 425 miljoen mensen met type 2 diabetes en naar verwachting zullen dit er in 2045 642 miljoen zijn. Vanwege de klassieke (cardiovasculaire) complicaties, comorbiditeiten en prevalentie zijn de gevolgen van type 2 diabetes groot voor de patiënt, het zorgsysteem en de samenleving. Daarnaast heeft een groot aantal mensen zonder het te weten een voorstadium van diabetes, dat prediabetes wordt genoemd. De prevalentie van prediabetes neemt in gelijke mate toe en geeft ook een groter risico op het krijgen van klassieke complicaties en mogelijk ook van comorbiditeiten. Daarmee begint de verhoogde ziektelast dus eigenlijk al in prediabetes. Om nieuwe aangrijpingspunten voor behandeling en preventie te kunnen identificeren is meer inzicht in de onderliggende cardiovasculaire mechanismen in prediabetes, type 2 diabetes en de bijbehorende ziektelast noodzakelijk.

Het is belangrijk om te realiseren dat cardiovasculair risico niet alleen geldt voor individuen met type 2 diabetes of prediabetes maar ook voor de individuen zonder en dat we kunnen leren van onderliggende mechanismen van verhoogd cardiovasculair risico te onderzoeken in een groot cohort gebaseerd op de algemene populatie dat bestaat uit individuen met en zonder (pre)diabetes. Dit proefschrift richt zich op onderzoek van de cardiovasculaire mechanismen onderliggend aan de toegenomen ziektelast in individuen met en zonder (pre)diabetes. De focus ligt op de rol van nieuwe markers van verschillende elementen van cardiovasculaire functie in een uitgebreid gekarakteriseerd cohort gebaseerd op de algemene populatie.

In het licht van bovenstaande had dit proefschrift drie doelstellingen. Ten eerste, meer inzicht krijgen in de ziektelast in (pre)diabetes gedefinieerd als de aanwezigheid van comorbiditeiten in aanvulling op klassieke complicaties en cardiometabole risicofactoren. Dit is niet eerder uitgebreid en kwantitatief onderzocht en vergeleken is 
met individuen met een normaal glucose metabolisme op het niveau van de algemene populatie (hoofdstuk twee). Ten tweede, om meer inzicht te verkrijgen in het toegenomen cardiovasculaire risico in (pre)diabetes op het niveau van de algemene populatie. Dit toegenomen risico kan deels worden verklaard door de goed bekende cardiovasculaire risicofactoren zoals een hoog cholesterol en factoren van cardiovasculaire functie zoals stijve vaten (arteriële vaatstijfheid) en een veranderde structuur van de linkerhartkamer. Het is echter minder duidelijk of nieuwere markers van cardiovasculaire functie ook bijdragen aan de pathofysiologie van het toegenomen cardiovasculaire risico van individuen met (pre)diabetes in de algemene populatie, te weten de drukafhankelijkheid van arteriële (carotis) vaatstijfheid (hoofdstuk drie) en de structuur en functie van het rechterhart (hoofdstuk vier). Ten derde, het bestuderen van de relaties tussen cardiale functie en comorbiditeiten die geassocieerd zijn met type 2 diabetes, en wat de rol van (pre)diabetes daarin is, op het niveau van de algemene populatie. Het hart heeft een centrale functie in het lichaam en beïnvloedt alle organen. In dit proefschrift bestuderen we de relatie tussen cardiale functie en cognitief functioneren (hoofdstuk vijf), en cardiale functie en cardiorespiratoire fitheid (hoofdstuk 6 ) in de algemene populatie, met aandacht voor de rol van (pre)diabetes daarin.

Alle vraagstellingen in dit proefschrift werden onderzocht met behulp van crosssectionele gegevens van De Maastricht Studie. Dit is een grootschalig lopend onderzoek op het niveau van de algemene populatie naar type 2 diabetes en andere chronische aandoeningen. Het onderzoek wordt uitgevoerd bij personen van 40-75 jaar die woonachtig zijn in de regio Maastricht-Heuvelland. Een grootschalig onderzoek op het niveau van de algemene populatie met een epidemiologische benadering heeft verschillende voordelen. Het geeft de mogelijkheid om uitgebreid verschillende determinanten en uitkomsten te bepalen en te onderzoeken. Daarbij is de kans op foutieve veronderstellingen (bias) in de onderzochte associaties kleiner omdat er gecorrigeerd kan worden voor veel verschillende confounders. Daarnaast kunnen de bevindingen tenminste vertaald worden naar de bronpopulatie en mogelijk ook de algemene populatie.

\section{Belangrijkste bevindingen en hun interpretatie}

In hoofdstuk 2 onderzochten we uitgebreid de ziektelast in (pre)diabetes gedefinieerd als de aanwezigheid van 15 niet-klassieke comorbiditeiten, 6 klassieke complicaties en 10 cardiometabole risicofactoren op het niveau van de algemene populatie. We vonden onafhankelijk van leeftijd en geslacht een aanzienlijk grotere ziektelast in niet alleen type 2 diabetes maar ook in prediabetes. Deze ziektelast bestaat inderdaad voor een belangrijk deel uit niet-klassieke comorbiditeiten in aanvulling op klassieke complicaties en cardiometabole risicofactoren. Dit wordt geïllustreerd door drie bevindingen. Als 
eerste, $49 \%$ van de individuen met type 2 diabetes had 3 of meer comorbiditeiten in vergelijking tot $20 \%$ van de individuen zonder (pre)diabetes. Ten tweede, $61 \%$ van de individuen met type 2 diabetes had een totale ziektelast score van acht of meer in vergelijking tot $21 \%$ van de individuen zonder (pre)diabetes. Ten derde, in individuen met prediabetes lag de toegenomen comorbiditeiten en ziektelastscore op een derde tot de helft van die in individuen met type 2 diabetes. Daarmee benadrukken deze bevindingen het belang van de bewustwording van zorgprofessionals dat er een relatie is tussen (pre)diabetes en niet-klassieke comorbiditeiten; de noodzaak tot verder onderzoek naar de mogelijke oorzakelijke rol van hyperglykemie in het voorkomen van comorbiditeiten, en naar interventies die onderzoeken of het verminderen van de hyperglykemie ook leidt tot verminderd voorkomen van comorbiditeiten en ziektelast.

In de hoofdstukken drie en vier was het doel om meer inzicht te verkrijgen in de onderliggende pathofysiologische mechanismen van het toegenomen cardiovasculaire risico in (pre)diabetes op het niveau van de algemene populatie.

In hoofdstuk drie onderzochten en bevestigden we de hypothese dat de drukafhankelijkheid van carotisstijfheid (gemeten als het systolische-diastolische verschil in polsgolfsnelheid met vaatechografie, $\delta$ pulse wave velocity, $\delta P W V)$ groter is in type 2 diabetes. Type 2 diabetes is een setting met verhoogde reorganisatie van de arteriële vaatwandmatrix waarbij elastinedegradatie en collageencross-linking optreedt. De resultaten toonde dat type 2 diabetes, maar niet prediabetes, geassocieerd is met een grotere drukafhankelijkheid van carotisstijfheid onafhankelijk van traditionele cardiovasculaire risicofactoren. Daarbij is het belangrijk dat de associatie niet verdwijnt na aanvullende correctie voor carotisstijfheid (gemeten als carotis PWV). Deze bevinding suggereert dat de drukafhankelijkheid van carotisstijfheid gemeten als SPWV additionele informatie bevat betreffende de reorganisatie van de arteriële vaatwandmatrix naast carotisstijfheid, en dus kan bijdragen aan het toegenomen cardiovasculaire risico in (pre)diabetes. Toekomstige prospectieve studies zijn nodig om de relatieve bijdragen van elastinedegradatie en collageencross-linking te onderzoeken door ook factoren zoals plasmabiomarkers voor oxidatieve stress, chronische laaggradige inflammatie en endotheeldisfunctie te includeren in de analyses.

In hoofdstuk vier onderzochten we of (pre)diabetes is geassocieerd met veranderingen in het hart van linkeratrium, linkerventrikel, rechteratrium en rechterventrikel structuur en functie (gemeten met echocardiografie). We onderzochten de hypothese dat veranderingen van het rechterhart in (pre)diabetes kunnen worden verklaard door veranderingen van de linkerventrikel. De resultaten toonden dat (pre)diabetes geassocieerd is met structurele rechteratrium en rechterventrikel veranderingen en verminderde rechterventrikel systolische en diastolische functie. De associaties werden grotendeels niet statistisch significant verklaard door veranderingen in de linkerventrikel structuur en functie of pulmonale druk. Deze bevindingen suggereren dat (pre)diabetes het rechteratrium en de rechterventrikel structuur en 
functie kan beïnvloeden door directe myocardiale betrokkenheid, en dat deze veranderingen in de rechterharthelft dus ook mogelijk bijdragen aan het toegenomen cardiovasculaire risico in (pre)diabetes. Toekomstige prospectieve studies zijn nodig om de exacte onderliggende myocardiale effecten betrokken in de structurele en functionele veranderingen van het rechterhart in (pre)diabetes te onderzoeken inclusief de rol van microvasculaire disfunctie.

In de hoofdstukken vijf en zes was het doel meer inzicht te verkrijgen in de relaties tussen cardiale functie en comorbiditeiten die geassocieerd zijn met type 2 diabetes, en de rol van (pre)diabetes daarin, op het niveau van de algemene populatie.

In hoofdstuk vijf onderzochten we de relatie tussen biomarkers van cardiale schade (gemeten als NT-proBNP en troponine $\mathrm{T}$ in het bloed) en cognitieve performance (gemeten als de cognitieve domeinen geheugen, informatieverwerkingssnelheid, uitvoerende functie en aandacht met cognitieve testen) en structurele breinveranderingen (gemeten als volumeveranderingen op een MRI brein) op het niveau van de algemene populatie. We onderzochten of leeftijd de associatie tussen biomarkers van cardiale schade en zowel domeinen van cognitieve performance als structurele breinveranderingen modificeert. We testten de hypothese dat het concept van de hartbrein as continu is gedurende het leven en mogelijk wordt gemodificeerd door (pre)diabetes. De resultaten toonden dat hogere levels van biomarkers van cardiale schade geassocieerd waren met lagere scores op de domeinen van cognitieve performance in oudere maar niet in jongere individuen. Echter, hogere levels van biomarkers van cardiale schade bleken geassocieerd te zijn met structurele breinveranderingen in zowel jongere als ouderen individuen. De bevindingen waren onafhankelijk van educatie niveau, cardiovasculaire en levensstijl risicofactoren, zelfs na het excluderen van individuen met hartziekte, atriumfibrilleren of een beroerte in de voorgeschiedenis. De associaties werden ook niet gemodificeerd door (pre)diabetes. Onze bevindingen benadrukken daarmee de rol en de continue aard van de hart-brein as in de ontwikkeling van cognitieve achteruitgang. Daarnaast suggereren ze dat biomarkers van cardiale schade gebruikt zouden kunnen worden als biomarkers voor het inschatten van het risico op het ontwikkelen van cognitieve achteruitgang in zowel jongeren als oudere individuen. Toekomstige prospectieve studies zijn nodig om de exacte cardiovasculaire onderliggende mechanismen te onderzoeken; om de bruikbaarheid van biomarkers van cardiale schade als mogelijke targets in preventieve en therapeutische strategieën van cognitieve achteruitgang te testen; en om te onderzoeken of deze strategieën ook cognitieve achteruitgang kunnen voorkomen of verminderen.

In hoofdstuk zes onderzochten we de relatie tussen structurele en functionele maten van linkerventrikel diastolische functie (gemeten met echocardiografie) en cardiorespiratoire fitheid (gemeten met een submaximale fietstest) op het niveau van de algemene populatie. We onderzochten de hypothese dat afgenomen linkerventrikel 
diastolische functie bijdraagt aan een afgenomen cardiorespiratoire fitheid op het niveau van de algemene populatie en deze associatie kan verschillen tussen individuen met en zonder (pre)diabetes. De resultaten toonden dat een hogere gemiddelde E/e'ratio (functionele maat voor linkerventrikel diastolische functie) was geassocieerd met een lagere cardiorespiratoire fitheid, onafhankelijk van cardiovasculaire risicofactoren, levensstijlfactoren, cardiale pathologie en (pre)diabetes. Meer structurele veranderingen in linkeratrium en linkerventrikel (structurele maten van linkerventrikel diastolische functie) en de maximale tricuspidalisklepinsufficiëntie-stroom waren geassocieerd met betere cardiorespiratoire fitheid in individuen zonder (pre)diabetes, maar niet in individuen met (pre)diabetes. Onze bevindingen suggereren dat verminderde linkerventrikel diastolische functie bijdraagt aan het pathofysiologische proces van verminderde cardiorespiratoire fitheid in de algemene populatie. Daarbij suggereren onze resultaten dat de maximale tricuspidalisklepinsufficiëntie-stroom en veranderingen in linkeratrium en linkerventrikel niet geschikt zijn voor het definiëren van vroege linkerventrikel diastolische disfunctie in de algemene populatie. De verschillen in de associaties van structurele maten van linkerventrikel diastolische functie met cardiorespiratoire fitheid in (pre)diabetes ten opzichte van individuen zonder (pre)diabetes zouden verklaard kunnen worden door de-afwezigheid van cardiale structurele adaptatie om effectief de cardiorespiratoire fitheid te verhogen in (pre)diabetes. Toekomstige prospectieve studies zijn nodig om de bruikbaarheid van linkerventrikel diastolische functie als mogelijke target in preventieve en therapeutische strategieën voor verminderde cardiorespiratoire fitheid op het niveau van de algemene populatie en in (pre)diabetes, en of deze strategieën verminderde cardiorespiratoire fitness kunnen voorkomen of verbeteren.

\section{Conclusies}

Concluderend, in dit proefschrift is op het niveau van de algemene populatie de grotere ziektelast in (pre)diabetes gekwantificeerd en is er meer inzicht verschaft in enkele onderliggende cardiovasculaire mechanismen van de verhoogde ziektelast, in individuen met en zonder (pre)diabetes. Dit proefschrift benadrukt het belang dat gezondheidsprofessionals zich bewust moeten zijn van het voorkomen van comorbiditeiten als onderdeel van de ziektelast in individuen met (pre)diabetes en zowel multimorbiditeit als prediabetes moeten meenemen in hun behandeldoelen. Alle associaties in dit proefschrift zijn gebaseerd op cross-sectionele data waardoor er geen directe uitspraken gedaan kunnen worden over oorzaak-gevolg. Hiervoor zijn longitudinale (prospectieve) onderzoeken nodig. Deze toekomstige prospectieve studies zijn nodig om de exacte mechanismen verder te onderzoeken om aangrijpingspunten voor behandeling en preventie van (pre)diabetes en de grotere ziektelast te 
identificeren, en om de bruikbaarheid van de cardiovasculaire functie markers uit dit proefschrift in preventie en therapie strategieën beter te begrijpen. Daarnaast zouden toekomstige studies zich moeten focussen op interventies om vast te stellen of het aangrijpen van hyperglykemie en deze cardiovasculaire markers de ziektelast kan verminderen. 